\title{
Influence of Hydropower Development on Flow Regime in the Zambezi River Basin for Different Scenarios of Environmental Flows
}

\author{
T. Cohen Liechti • J. P. Matos • J.-L. Boillat • \\ A. J. Schleiss
}

Received: 4 February 2014 / Accepted: 13 October 2014 /

Published online: 18 October 2014

(C) Springer Science+Business Media Dordrecht 2014

\begin{abstract}
As the need for energy is increasing, the challenges in the future are to operate existing large hydraulic schemes in more sustainable ways and to develop future water resources projects that are able to achieve a better balance between environmental and socio-economic demands. In this context, scenarios combining different levels of environmental requirements as well as hydropower developments were simulated at a daily time step with a hydraulic-hydrological model (the Soil and Water Assessment Tool) over the Zambezi River Basin. For each scenario, the hydropower operation rules, the mean annual energy produced and the firm powers were considered. The impact on the flow regime was characterized by a hydrological alteration indicator and Pardé coefficients. In the present state, the total mean annual energy production is about 30,000 GWh with a firm power of about 3,000 MW. The impact of the dams on the flow regime is low in the Kafue flats and the Zambezi delta and high in the Mana Pools. The new runof-river hydropower plants aim to increase the mean energy production by more than $90 \%$ and the firm power by about $40 \%$. Releasing e-flows can reduce the impact in the Kafue flats and in the Zambezi delta, with a loss of less than $10 \%$ of mean annual energy production and about $15 \%$ of the firm power at Itezhi-Tezhi and Cahora Bassa. This reveals that a compromise between energy production and environmental sustainability can be reached.
\end{abstract}

Keywords Water management $\cdot$ Numerical modeling $\cdot$ Anthropogenic effects $\cdot$ Zambezi $\cdot$ Dam operational rules $\cdot$ SWAT

\section{Introduction}

Hydroelectric power dams currently provide $20 \%$ of the world's electricity supply (International Commission On Large Dams 2007). However, the alteration of river flow regimes caused by

T. Cohen Liechti $(\bowtie) \cdot$ J. P. Matos $\cdot$ J.-L. Boillat $・$ A. J. Schleiss

Laboratory of Hydraulic Constructions (LCH), Ecole Polytechnique Fédérale de Lausanne (EPFL),

Station 18, CH-1015 Lausanne, Switzerland

e-mail: theocohen@gmail.com

J. P. Matos

SHRH, Instituto Superior Técnico (IST), Avda. Rovisco Pais, Lisbon 1049-001, Portugal 
dams is considered one of the causes of the degradation of freshwater ecosystems worldwide (D Harrison et al. 2007). As the need for further water services increases, the challenge for the future is to avoid past mistakes (International Commission On Large Dams 2012; United Nations Development Programme 2006). New methods to implement participatory decision for water resources management in transboundary basins are developed (Comair et al. 2014).

'The concept of environmental flows (e-flows) has been advanced to meet ecosystem demands for water. E-flows are defined as the volume of water that should flow in a river and its variation over time to maintain specific indicators of ecosystem health' (Yin et al. 2012). In the past, e-flows were defined as a single minimum 'compensation' or 'reserved' flow. Nowadays, experts have reached a consensus: e-flows should represent the fullest possible range of natural flow variations, taking into account the magnitude, frequency, timing, duration and rate of change of the flow regime (Arthington et al. 2006; Yin et al. 2012).

Several methodologies for evaluating natural flows and quantifying the effect of dams on flow alteration have been suggested. They are mainly based on aquatic ecology theory and require as their starting point either measurements or synthesized daily streamflows from a period with no human perturbations on the hydrological regime. The Range of Variability Approach (RVA) characterizes the flows using 32 different parameters derived from long term ( $>20$ years) daily streamflow records defining the natural flow variables (Richter and Thomas 2007; Richter et al. 1997).

An approach combining reservoir operation rules and e-flows release was developed to optimize e-flow provision under given water supply constraints (Yin et al. 2011; 2012). The flows were divided into four functional components, namely floods, high-flow pulses, base flows and extremely low flows. The flow regime alteration was quantified by RVA (Richter et al. 1997), deriving the range of variation for each hydraulic indicator from the natural hydrograph.

Optimization of hydroelectric operations has already been applied to large river basins and multi-reservoir systems (Ostadrahimi et al. 2012; Zhang et al. 2013). In the Zambezi Basin, optimal flow allocation was assessed by pricing the irrigated land and the generated energy, considering the environmental flow as a constraint (Gandolfi et al. 1997) or setting a value for the flooded area (Tilmant et al. 2010; Tilmant et al. 2012). The impact of different economic development scenarios on energy production was assessed (Beilfuss 2010; The World Bank 2010). However, since discussions are ongoing on the future operating rules of Cahora Bassa, related to the new dam planned downstream (Mphanda Nkuwa), further studies are still needed.

The goal of the present approach is to assess the future hydrological behavior of the basin at a daily time step through model simulations. A comprehensive set of scenarios combining different levels of environmental requirements as well as multiple hydropower development schemes is developed. The short time step is of high importance, considering that future hydropower production will fluctuate more, following energy demand and prices. Moreover, the simulations can consider the hydropower operation precisely, which is difficult with optimization models. The hydrologic-hydraulic model is used to assess the flow changes not only in the Zambezi delta but also at the Kafue flats and the Mana Pools, resulting in a more complete analysis in comparison to earlier studies.

\section{Case Study and Tools}

\subsection{The Zambezi Water Resources System}

The Zambezi River Basin (Fig. 1) is the fourth largest drainage basin in Africa. Totaling an area of $1.4 \mathrm{M} \mathrm{km}^{2}$, it is shared by eight nations: Zambia (40.7 \%), 


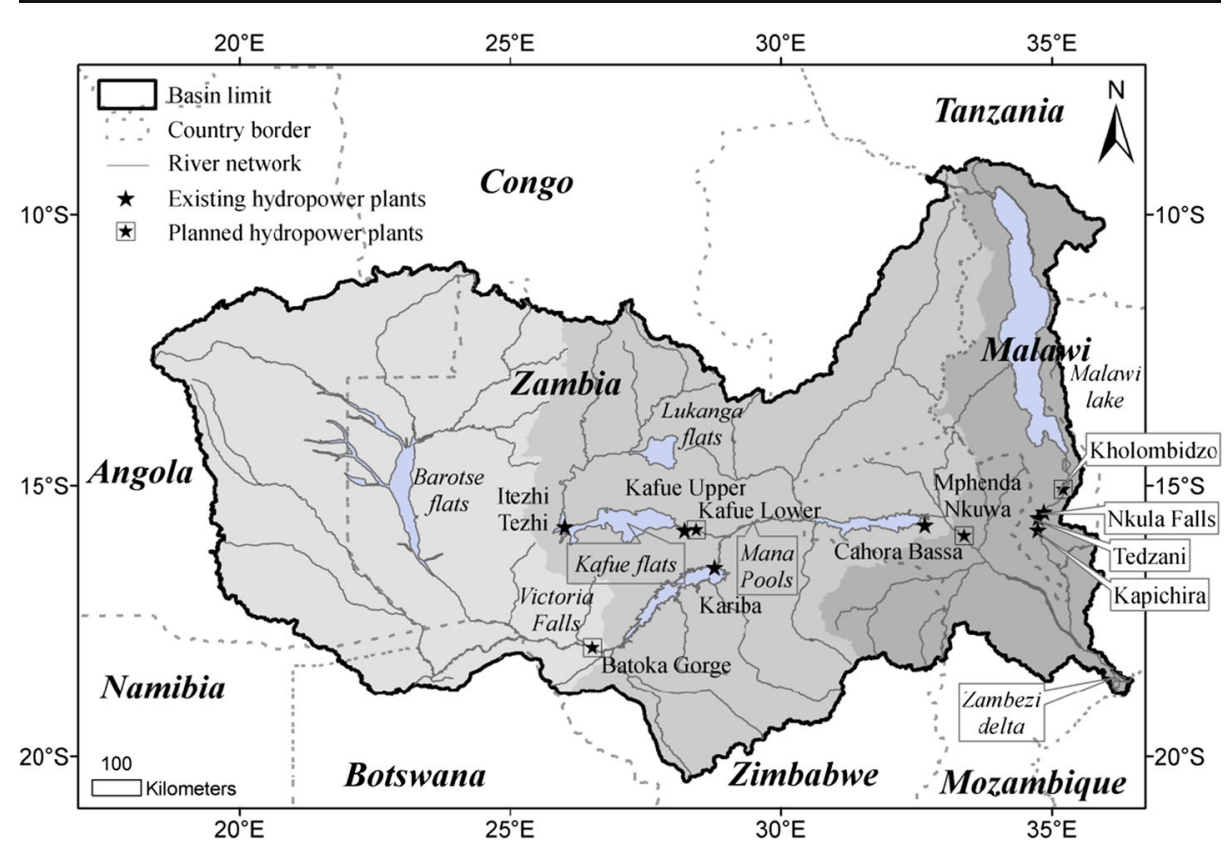

Fig. 1 Map of the Zambezi River Basin showing the river network, the principal flats and lakes, the check points, the country borders and the main existing hydropower schemes as well as the planned projects. The Upper, Middle and Lower Zambezi regions are in different shade of gray

Angola (18.3\%), Zimbabwe (15.9\%), Mozambique (11.4 \%), Malawi (7.7 \%), Botswana (2.8\%), Tanzania (2.0\%) and Namibia (1.2\%) (Vörösmarty and Moore III 1991). The basin can be separated into three distinct stretches: the Upper Zambezi, the Middle Zambezi and the Lower Zambezi (Beilfuss and Dos Santos 2001; Moore et al. 2007). The four largest dams already built on the basin are Kariba, Kafue, Itezhi-Tezhi and Cahora Bassa. Numerous small run-of-river power plants are implemented on the Shire River, downstream of the Malawi Lake. Still, there is a acknowledgeable potential for hydropower development and several projects will be commissioned in the next 20 years. The characteristics of the existing and projected hydropower plants included in the model are summarized in Table 1 based on information from the "The Zambezi river basin: a multi-sector investment opportunities analysis" report (The World Bank 2010) and other studies (Beilfuss 2010; G P Harrison and Whittington 2002). The planned new hydropower projects introduced in the model (Batoka Gorge, Kafue Gorge Lower, Mphanda Nkuwa and Kholombidzo) have no significant retention capacity and will operate as run-of-river plants maximizing firm power delivery on a system level. Four capacity increases of existing hydropower plants are additionally considered: Kariba North and South bank extensions, Itezhi-Tezhi power extension, Cahora Bassa North Bank extension and Kapichira extension.

Three check points for the discharge analysis were defined based on previous studies (Beilfuss 2010; 2012; Beilfuss and Brown 2010; The World Bank 2010; Tilmant et al. 2012), namely the Kafue flats, the Mana Pools and the Zambezi delta. All of them are influenced by at least one of the existing or future hydropower schemes. 


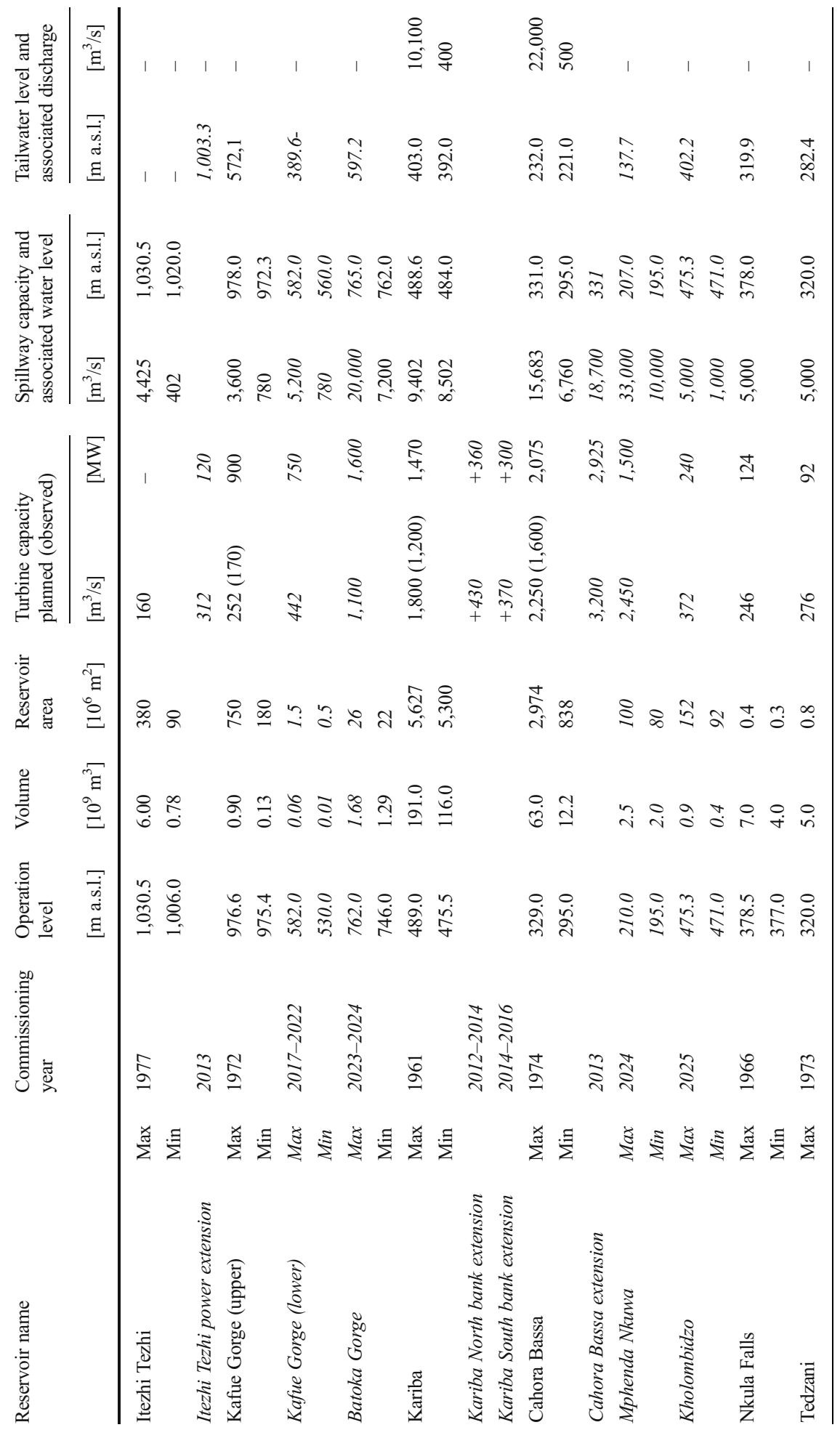




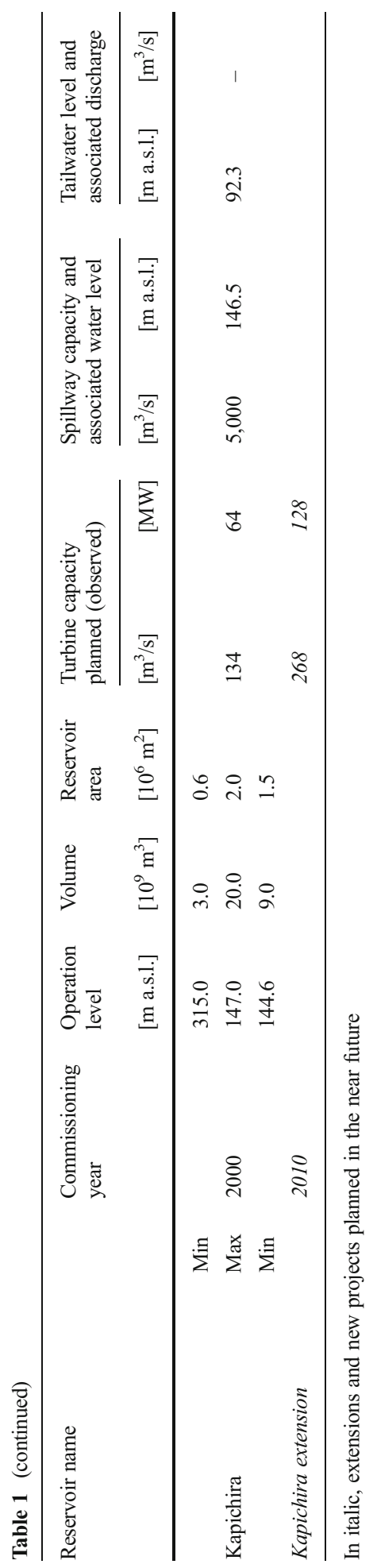


2.2 The Hydrologic-Hydraulic Model

\subsubsection{SWAT 2009}

The Soil and Water Assessment Tool (SWAT) has been chosen to simulate the hydrological behavior of the basin. The following demands led to the selection of this tool: (1) a model already applied in Africa with promising results which would contribute to an appropriate definition of the hydrological processes (Dessu and Melesse 2012; Mango et al. 2011; Schuol et al. 2008) and (2) a source code available in the public domain allowing the model transfer to the stakeholders (http://swat.tamu.edu/software/swat-model/).

SWAT 2009 is a semi-distributed physically based continuous time model described in detail in the user manual (Arnold et al. 1998; Neitsch et al. 2009). The model uses hydrologic response units (HRUs) to describe the spatial heterogeneity in land cover, soil types and terrain slopes within a watershed. The model estimates the water balance in each HRU for four storage volumes (snow, soil profile, shallow aquifer and deep aquifer) by considering processes of precipitation, interception, evapotranspiration, surface runoff, infiltration, percolation and subsurface runoff. In its present implementation, it estimates surface runoff based on the Soil Conservation Service (SCS) curve number procedure (USDA Soil Conservation Service 1972), being the potential evaporation calculated based on the Hargreaves method (Hargreaves and Samani 1985).

In the present study, three global data sets were used to define the sub-basins and the HRUs: (1) the Digital Elevation Model (DEM) from the United States Geological Survey's (USGC) public domain geographical database HYDRO1k, at a spatial resolution of $1 \mathrm{~km}$ (http://eros. usgs.gov/\#/Find_Data/Products_and_Data_Available/gtopo30_info), (2) the soil map produced by the Food and Agriculture Organization of the United Nations (FAO 1995) and (3) the land-use grid from the Global Land Cover Characterization (GLCC, Version 2, http:// edcsns17.cr.usgs.gov/glcc/). A minimum drainage area unit of $5,000 \mathrm{~km}^{2}$ was first set to define the sub-basins which were refined around the lakes and the floodplains, increasing the number of sub-basins to a total of 405 and the HRUs to 778 units. The artificial and natural lakes, as well as the important floodplains located on the main channel, were modeled as reservoirs with different characteristics.

TRMM 3B42 version 7a, NASA's standard precipitation product was selected as the precipitation source according to a previous reliability analysis (Cohen Liechti et al. 2012). The temperature grids were derived from NCEP/DOE 2 Reanalysis data (Kanamitsu et al. 2002) provided by the NOAA/OAR/ESR.

\subsubsection{Reservoir Model}

A modified reservoir model was developed to simulate the floodplain hydrology (Cohen Liechti et al. 2014). Furthermore a hydropower model was implemented to compute the outflow from the dams depending on the reservoir rule curve and limit operation levels. The inputs of the hydropower model are (1) the minimum and the maximum operation levels with their associated volumes and surface area, (2) the minimum and maximum tailwater levels with the associated discharges, (3) the maximum spillway discharge at the minimum and maximum operation levels, (4) the turbine maximum capacity, (5) the monthly target level and (6) the time needed to reach the target storage. Based on these values, linear relations are adjusted in order to calculate the reservoirs' state corresponding to given water volumes. The operation rules are defined based on the difference between the reservoir volume $(\operatorname{Vol}(t))$, the target volume which is the desired volume according to the operation rules $\left(\operatorname{Vol}_{\text {targ }}\right)$, the 
reservoir minimum operation volume $\left(\mathrm{Vol}_{\min }\right)$ and the reservoir maximum operation volume $\left(V o l_{\max }\right)$. Two operation rules can be chosen depending on whether the target rule curve is used as a constraint or not (Table 2).

In the first option, the operation rules are taking into account the target volume only as a maximum volume constraint and they allow the volume to decrease below this as long as it stays above the minimum operation volume. As an alternative, the operation rules take into account the target volume as the objective volume at each time step. The range of variability around the target volume depends on the defined time to reach it.

Once the turbine and spilled discharges are obtained, the tailwater level is calculated. The available head (Head) is defined as the difference between the reservoir water level and the tailwater level. The power generated at time $t$ can be determined by the following equation:

$$
\text { Power }=\eta \cdot g \cdot \rho \cdot \text { Head } \cdot \text { Qturb }
$$

where $\eta$ is the turbine efficiency, $g$ is the gravitational acceleration $\left[\mathrm{m} / \mathrm{s}^{2}\right]$ and $\rho$ is the water density $\left[\mathrm{kg} / \mathrm{m}^{3}\right]$.

\subsubsection{Model Calibration}

The model was calibrated over the period 1998 to 2006 based on discharge data provided by the Global Runoff Data Centre (GRDC) (Fekete et al. 1999) and the Department of Water Affairs of Zambia (DWA, personal communication). The calibration procedure was defined in three steps. At first, the model parameters to optimize were chosen. Secondly, the objective functions were defined based on the future model use and thirdly an algorithm was implemented to find the "best" parameter sets.

The following performance indicators were used in the calibration procedure: the relative error, the Nash-Sutcliffe efficiency coefficient and the volume ratio. The multi-algorithm genetically adaptive multi-objective method (AMALGAM) was chosen as the heuristic search algorithm (Vrugt and Robinson 2007; Vrugt et al. 2009).

To take into account the uncertainty of the calibration, multiple optimal parameter sets (Pareto front), assumed equivalent in terms of calibration performance, were kept for the simulations. More details on the calibration procedure can be found in Cohen Liechti et al. (2014).

\section{Scenarios}

Three principal scenarios were defined, namely (A) a reference case considering the basin without hydraulic structures, (B) the present state (in 2010) including sub-scenarios with different environmental flow constraints, $(\mathrm{C})$ the future development taking into account the planned hydropower schemes as well as the on-going dam extensions along with sub-scenarios of environmental flows. All scenarios are simulated for a period of 13 years from 1998 to 2010 and evaluated regarding the generated energy as well as their impact on the flow regime at the check points.

\subsection{Environmental Flow}

The environmental flow constraints are normally defined in terms of mean monthly discharge (e-discharge) (Beilfuss and Brown 2010; Gandolfi et al. 1997; The World Bank 2010). These values were used as a basis for restoring a daily flood hydrograph considered as a constraint on the outflow at the hydropower plants. The e-flow hydrograph generation is based on the flood 
禀咅

这

(ิ)

E.

吾章

总

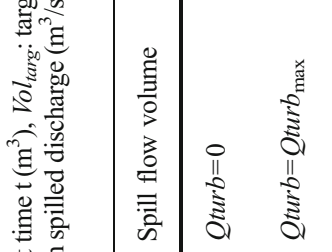
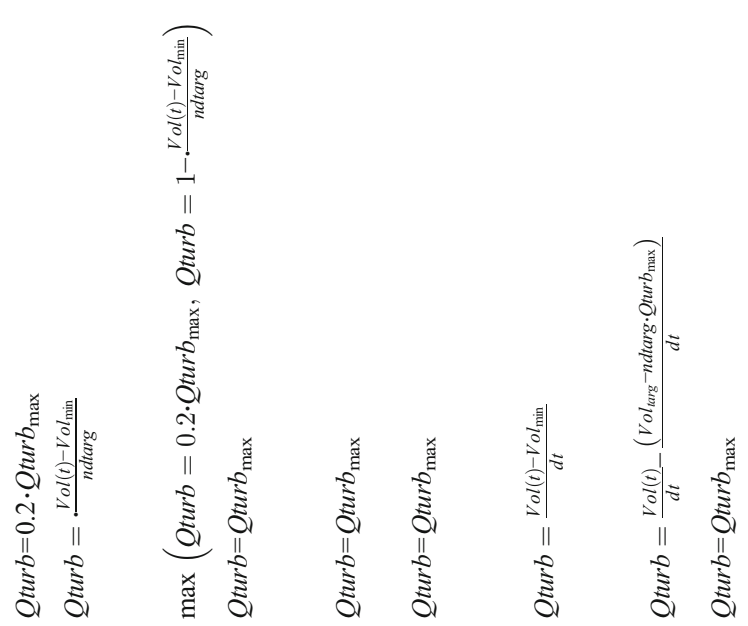

疍言

Ð

อิ ڤิ

in

을

焉

on

客密

원

동

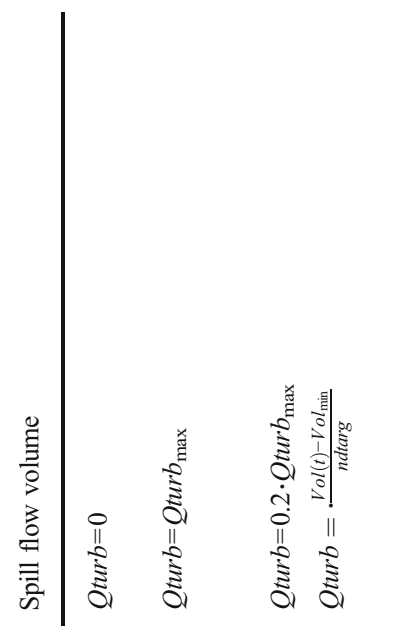

a

ఏ)

की

范

a 3

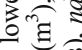

o

吉票

里

言

है है

ठ응

苛苛

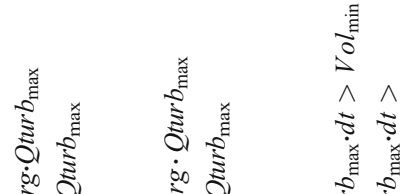

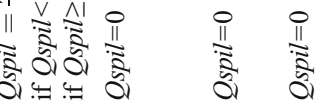

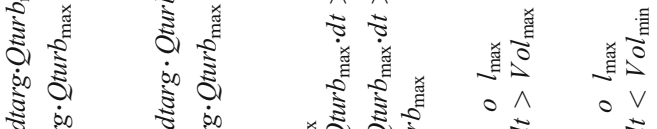

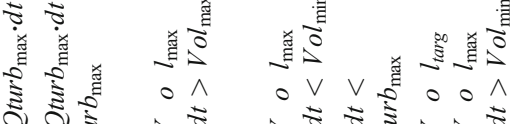

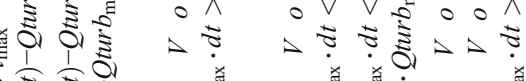

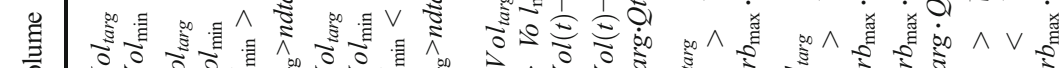

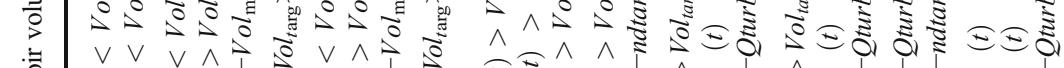

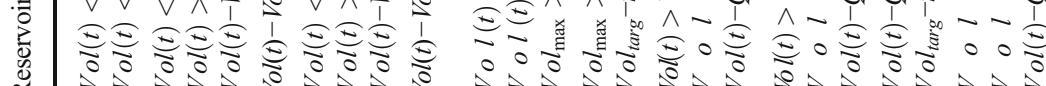




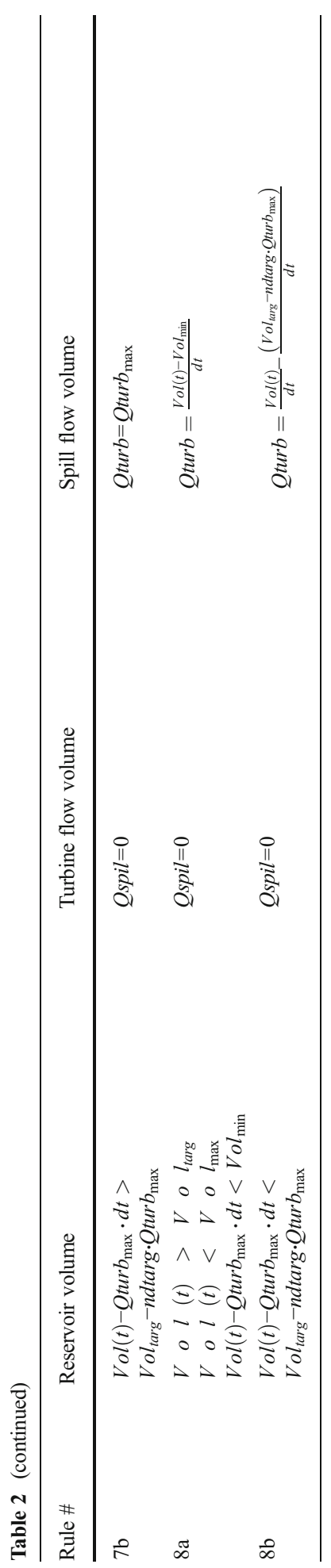


Table 3 Investigated scenarios of environmental flow

\begin{tabular}{|c|c|c|c|c|}
\hline Name & Description & $\begin{array}{l}\text { Environmental flow } \\
\text { at Itezhi Tezhi }\end{array}$ & $\begin{array}{l}\text { Environmental } \\
\text { flow at Kariba }\end{array}$ & $\begin{array}{l}\text { Environmental flow } \\
\text { at Cahora Bassa } \\
\text { (and Mphenda Nkuwa) }\end{array}$ \\
\hline E0 & $\begin{array}{l}\text { Existing } \\
\text { constraint }\end{array}$ & $\begin{array}{c}300 \mathrm{~m}^{3} / \mathrm{s} \text { during } 1 \text { month } \\
\left(\text { March), } 25 \mathrm{~m}^{3} / \mathrm{s} \mathrm{min}\right.\end{array}$ & - & - \\
\hline E1 & Low constraint & $\begin{array}{l}300 \mathrm{~m}^{3} / \mathrm{s} \text { during } 2 \text { months } \\
\text { (from mid-February to } \\
\text { mid-April), } 25 \mathrm{~m}^{3} / \mathrm{s} \text { min }\end{array}$ & - & $\begin{array}{l}4,500 \mathrm{~m}^{3} / \mathrm{s} \text { s during } 1 \\
\text { month (February) }\end{array}$ \\
\hline E2 & $\begin{array}{l}\text { Moderate } \\
\text { constraint }\end{array}$ & $\begin{array}{l}400 \mathrm{~m}^{3} / \mathrm{s} \text { during } 2 \text { months } \\
\text { (from mid-February to } \\
\text { mid-April), } 25 \mathrm{~m}^{3} / \mathrm{s} \text { min }\end{array}$ & $\begin{array}{r}2,500 \mathrm{~m}^{3} / \mathrm{s} \text { during } 1 \\
\text { month (February) }\end{array}$ & $\begin{array}{c}7,000 \mathrm{~m}^{3} / \mathrm{s} \mathrm{s} \text { during } 1 \\
\text { month (February) }\end{array}$ \\
\hline E3 & High constraint & $\begin{array}{l}500 \mathrm{~m}^{3} / \mathrm{s} \mathrm{s} \text { during } 2 \text { months } \\
\text { (from mid-February to } \\
\text { mid-April), } 25 \mathrm{~m}^{3} / \mathrm{s} \mathrm{min}\end{array}$ & $\begin{array}{l}2,500 \mathrm{~m}^{3} / \mathrm{s} \mathrm{s} \text { during } 2 \text { months } \\
\text { (February and March) }\end{array}$ & $\begin{array}{l}10,000 \mathrm{~m}^{3} / \mathrm{s} \text { s during } \\
1 \text { month (February) }\end{array}$ \\
\hline
\end{tabular}

duration, the starting date of the flood event and the e-discharge as defined in the literature (Beilfuss and Brown 2010; Gandolfi et al. 1997; The World Bank 2010). As the flooding patterns in the area are seasonal, the flood will naturally take place over a relatively long period. Therefore, the shape of the hydrograph is approximated as trapezoidal. The e-flow is released only if the volume of water in the reservoir exceeds $30 \%$ of the active storage or if it is higher than the target volume. If the calculated outflow based on the business as usual operation rules is above the desired e-flow, no additional constraints are given. Four levels of environmental satisfaction were simulated for each scenario (Table 3); the minimum constraint corresponding to the status quo.

\subsection{Indicators}

\subsubsection{Flow Alteration}

Based on the Range of Variability Approach (RVA) (Richter et al. 1997) and on the indicators derived by Yin et al. (2011, 2012), the flows are evaluated in terms of magnitude, timing, duration and volume of annual high flow conditions (Table 4). Since the major flow alteration caused by the reservoir operations occurs during the flood period, and considering that the eflows aim to recreate the effect of floods, the use of indicators related to low flow and monthly

Table 4 Indicators of hydrological alteration

\begin{tabular}{ll}
\hline Group & Indicators \\
\hline Group 1: Magnitudes of annual high flow conditions & Annual 1-day maximum flow $\left(D_{Q 1}\right)$ \\
& Annual 3-day maximum flow $\left(D_{Q 3}\right)$ \\
& Annual 7-day maximum flow $\left(D_{Q 7}\right)$ \\
& Annual 30-day maximum flow $\left(D_{Q 30}\right)$ \\
Group 2: Timing of annual high flow conditions & Date of annual 1-day maximum flow $\left(D_{\text {dateQ1 }}\right)$ \\
Group 3: Duration of annual high flow conditions & Fraction of the year during which the flow is \\
& above the flow threshold $\left(D_{Q \text { thres }}\right)$ \\
Group 4: Volume of annual flood & Cumulated volume of flow above the annual \\
& 30 -day maximum flow $\left(D_{\text {volQ30 }}\right)$
\end{tabular}


mean flows would mask the effects of e-flows. Therefore, the magnitude of high flow is evaluated only on the 1, 3, 7 and 30 days maximum flows. The threshold used to define the duration of the flood corresponds to the bankfull discharge of $300 \mathrm{~m}^{3} / \mathrm{s}$ at the Kafue flats (Beilfuss 2012; Tilmant et al. 2012), 2,500 $\mathrm{m}^{3} / \mathrm{s}$ for the Mana Pools (Tilmant et al. 2012) and $4,500 \mathrm{~m}^{3} / \mathrm{s}$ for the Zambezi delta (Beilfuss and Brown 2010).

The range of variation of each hydrological indicator is derived from the natural hydrological time series and is set as the flow management target. A range of the 75th and 25th percentiles of the natural daily flows has been recommended (Richter et al. 1998). The deviation of the impacted flow regime from the natural one is measured for each indicator by the degree of alteration $(D)$ :

$$
D=\frac{\left|N_{o}-N_{e}\right|}{N_{e}}
$$

where $N_{o}$ is the observed number of years in which the value of the hydrological indicator falls within the RVA target range (75th and 25th percentiles); and $N_{e}$ is the expected number of years in which the indicator value falls within the RVA target range (75th and 25th percentiles).

The overall impact $\left(D_{t o t}\right)$ is expressed as follows:

$$
D_{\text {tot }}=\frac{1}{H} \sum_{i=1}^{H} D_{i}
$$

where $\mathrm{H}$ is the number of hydrological indicators.

The degree of alteration of the flow regime can be separated into three classes: low $\left(\mathrm{D}_{\text {tot }}\right.$ between 0 and $33 \%)$, moderate $\left(\mathrm{D}_{\text {tot }}\right.$ between 33 and $\left.67 \%\right)$, and high $\left(\mathrm{D}_{\text {tot }}\right.$ between 67 and $100 \%$ ) (Richter et al. 1997; Richter et al. 1998).

The flow alteration is also evaluated in terms of annual distribution of the discharge by the monthly Pardé coefficients defined as the mean monthly discharge over the mean annual discharge (Matos et al. 2010; Meile et al. 2011):

$$
P C_{m, a}=\frac{Q_{\text {mean month m,a }}}{Q_{\text {mean annual a }}}
$$

where $1 \leq \mathrm{m} \leq 12$ indicates the month, and a indicates the year.

When the Pardé coefficient is close to one, it means that the flow during the month is close to the mean annual flow. When the coefficient is above or below one, the monthly flow is above or below the mean annual flow respectively.

\subsubsection{Energy Production}

The energy generated by the hydropower plants is evaluated by two indicators: the firm power and the total annual energy. The firm power is defined as the amount of generated power equaled or exceeded $95 \%$ of the year (346 days a year), in megawatts. The annual energy is the total energy generated during the year in gigawatt hours.

\section{Analysis of Simulation Results}

A Pareto set of parameter values issued from the calibration procedure was employed for the model's simulation. The variability associated with the different parameter sets regarding 
hydrological alteration and energy production lies between 2 and $7 \%$ and between 1 and $5 \%$, respectively. Thus the difference between the scenarios is considered as significant only if it exceeds $5 \%$.

Based on observations, the turbines were assumed to operate at $70 \%$ of their maximum capacity at all existing and planned hydropower schemes in order to take into account revisions and other non-availabilities.

\subsection{Present State}

Regarding energy production, about $30,000 \mathrm{GWh} /$ year are generated on the basin with a firm power of about 3,000 MW, which is similar to the results obtained by previous studies (The World Bank 2010; Tilmant et al. 2010). The hydropower plant with the highest production is Cahora Bassa, followed by Kariba and Kafue Gorge Upper. The run-of-river plants located on the Shire River (Nkula Falls, Tedzani, and Kapichira) produce only minor energy compared to the others.

Releasing e-flows decreases the annual energy as well as the firm power, depending on the precise e-flow recommendation. The implementation of e-flows at Itezhi-Tezhi does not significantly reduce the annual energy production at Kafue Gorge Upper. At Kariba, the medium and the high level e-flows cause a reduction of 13 to $15 \%$ of the firm power and a large increase of the spilled volume (70 to $180 \%$ ). At Cahora Bassa, the loss in firm power is significant for the high e-flow scenario ( $12 \%$ ), combined with a large increase of variability of the annual energy production. Compared to the previous studies which quantify the decrease in energy production as about $6 \%$ if e-flows are released at Itezhi-Tezhi and Kariba (Gandolfi et al. 1997) and as 6 to $10 \%$ if e-flows are released at Cahora Bassa (Beilfuss 2010; Tilmant et al. 2010), the values obtained in the present study are slightly lower. This is due to a finer implementation of the e-flows regarding the operation rules which allow the hydropower plants to maintain a higher production.

The indicators of hydrological alteration derived from the RVA allow the characterization of the effects of the dams. More precisely, in the present state without new e-flows release, the influence is low on the Kafue flats (0.31), high on the Mana Pools (0.80) and low on the Zambezi delta (0.23). Kariba is the hydropower plant that most affects the discharge of the Zambezi, since its reservoir holds the highest storage capacity (it is in fact the largest artificial reservoir in the world by volume) and transfers the flood volume to the dry season. At Cahora Bassa, the definition of fixed operation rules maximizing the water level in the model leads to more spillage than historically observed, but it is considered as a realistic operation of the hydropower plant. The consequence is a somewhat lower alteration of the flow in the delta than what is actually observed.

\subsection{Future State with Planned Projects}

The extension of the existing hydropower plants, increasing installed capacity, has the greatest effect at Cahora Bassa. It increases both the produced mean annual energy $(+30 \%)$ and the firm power $(+12 \%)$, reducing the spilled volume by nearly $70 \%$. At Kariba, the turbines in a new powerhouse completely avoid spillage but reduce the firm power by nearly $60 \%$ without increasing substantially the mean annual energy production. This is due to the limit of the minimum operation volume and hints that the increase of the installed capacity at the site has the main goal of supplying peak energy. The full capacity would be used only for a few hours per day and should therefore not influence significantly the mean annual energy, except for a part of the spillage which could be turbined. 
The construction of new hydropower plants, namely Batoka, Kafue Gorge Lower, Mphanda Nkuwa and Kholombidzo, increases the mean annual energy production by $93 \%$ compared to the present state scenario (Fig. 2). This value is very close to what has been estimated by the previous studies (The World Bank 2010; Tilmant et al. 2012). The firm power is also increased, by about $40 \%$, revealing the huge development potential.

The influence of e-flows on the hydropower production for the scenario with extensions of the existing hydropower plants and the scenario with new dams is presented in Fig. 2. The low e-flow constraint for the scenario with the new hydropower plants does not significantly affect the hydropower production. Medium to high e-flow constraints reduce the total firm power by 9 to $19 \%$ and the total mean annual energy by $5 \%$ compared to the scenario without e-flows. Itezhi-Tezhi, Cahora Bassa and Mphanda Nkuwa are the most affected dams, with decreases of 8,7 and $3 \%$ in mean annual energy and 18, 15 and $12 \%$ in firm power, respectively, for medium e-flows. The variability in energy production is increased by the e-flows constraints.

The new planned hydropower schemes have a limited reservoir capacity and will be operated as run-of-river dams. Their influence on the hydrological alteration is therefore negligible. The increase of the installed capacity of the existing schemes leads to more marked hydrological alterations than the present state. In the Zambezi delta, the reduction of high flows results in an increase of the mean hydrological alteration from 0.23 to $0.65(+181 \%)$. At the Mana Pools, the alteration worsens from 0.80 to 0.94 (+18\%). There is no influence of the upgrade at Kafue flats since no increase of capacity is planned at the upstream hydropower plant.

As can be seen by the Pardé coefficients (Fig. 3), the extension of the installed capacity has above all a negative influence at Cahora Bassa, transferring all the wet season flow (from February to April) to the dry season (from July to December). The resulting curve is nearly flat. At Kariba, the extension of the installed capacity results in higher discharge during the flood season (March to May) than during the dry season (November and December). This introduces a transfer of flow volume which does not exist in the present state.

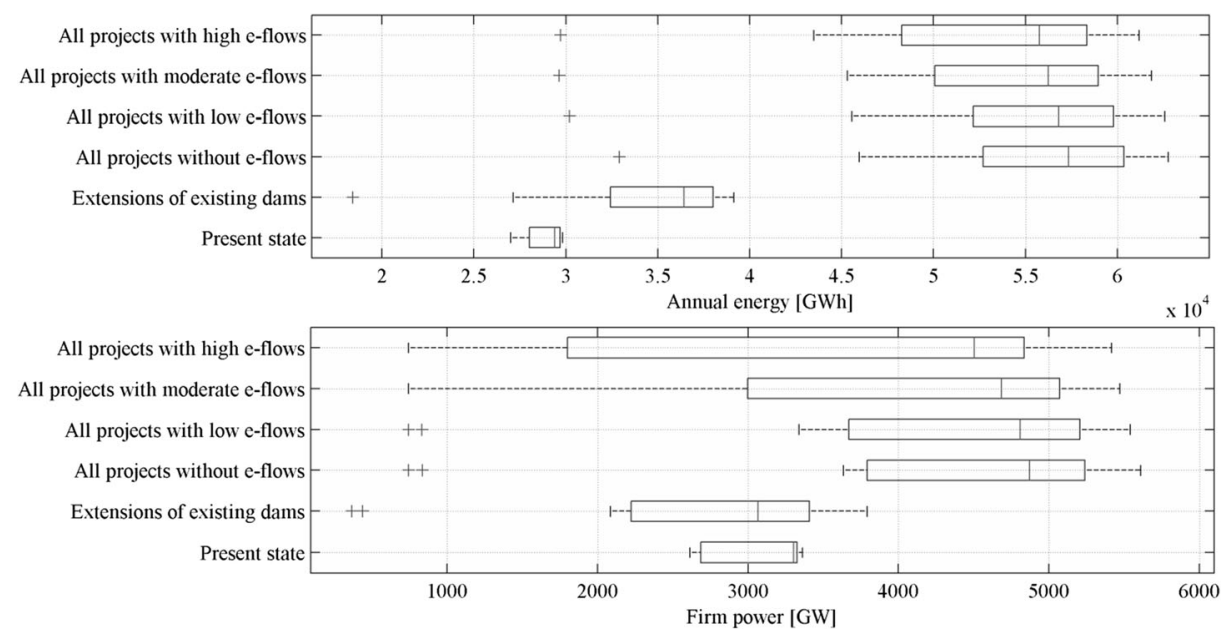

Fig. 2 Total annual energy production (above) and firm power (below) during the period 1998 to 2010 for the present state, with extension of existing dams and considering future additional hydropower plants, with three levels of e-flows 

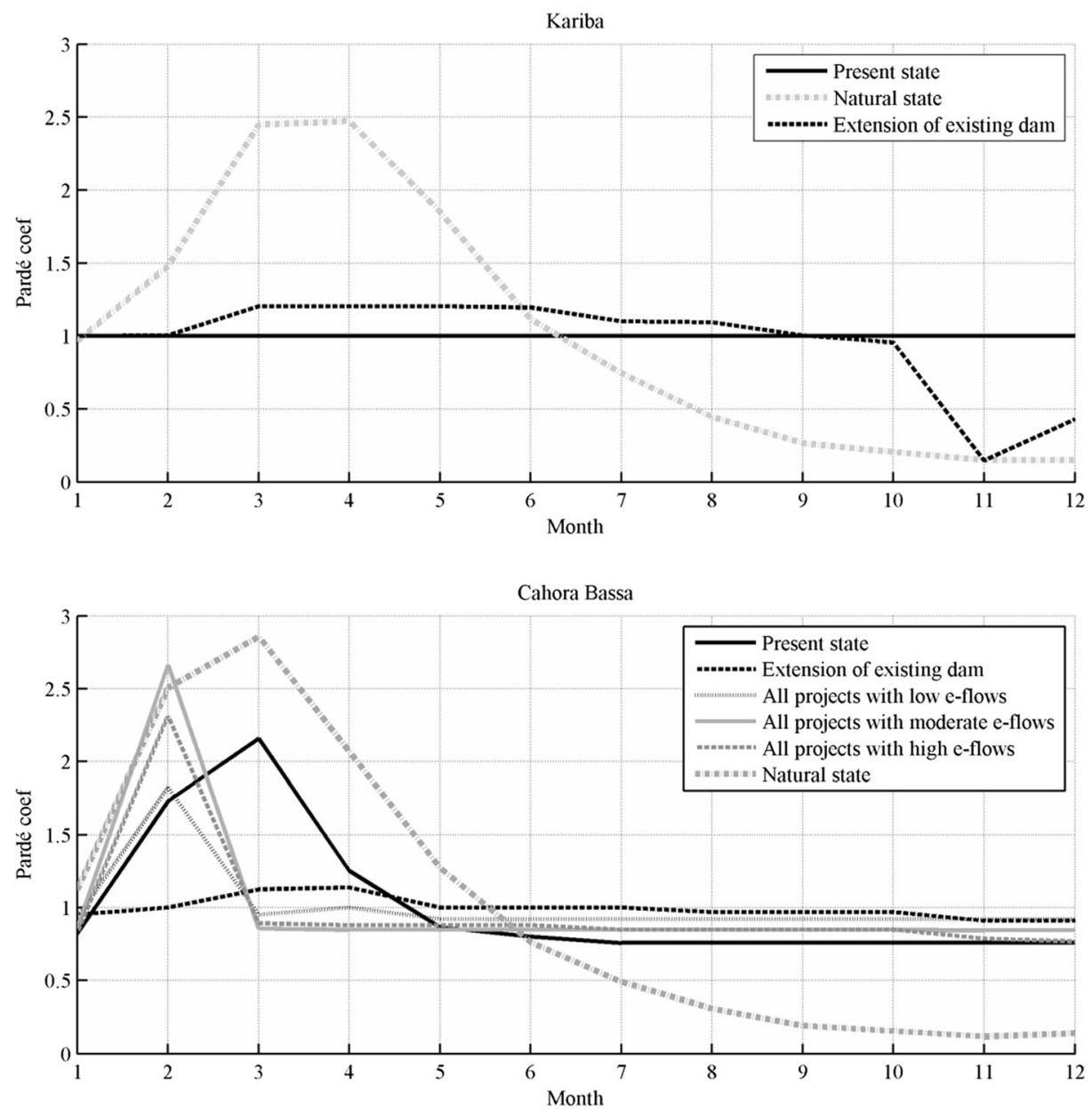

Fig. 3 Pardé coefficients at Kariba (above) and Cahora Bassa (below) for the future state scenario with e-flows in comparison with the present state

\subsection{Tradeoff Between Hydrological Alteration and Energy Production for Different E-flows}

Figure 4 shows the combined influence of all the hydropower plants in the present and future states on the hydrological regime at the Kafue flats downstream of Itezhi-Tezhi, at the Mana Pools downstream of Kariba and at the Zambezi delta downstream of Cahora Bassa. The mean hydrological alteration is zero for the natural condition without dams.

For the present state scenarios, the implementation of e-flows does not significantly reduce the hydrological alteration except for the high e-flows constraint which improves the situation at the Mana Pools and in the Kafue flats. The alteration increases in the Zambezi delta since the e-flows are too regular compared to the natural floods as released with the defined operation rules.

Including the extensions of the existing hydropower plants and the new dams increases the mean annual energy production by more than $90 \%$ and the mean hydrological alteration by about $40 \%$ compared to the present state. 


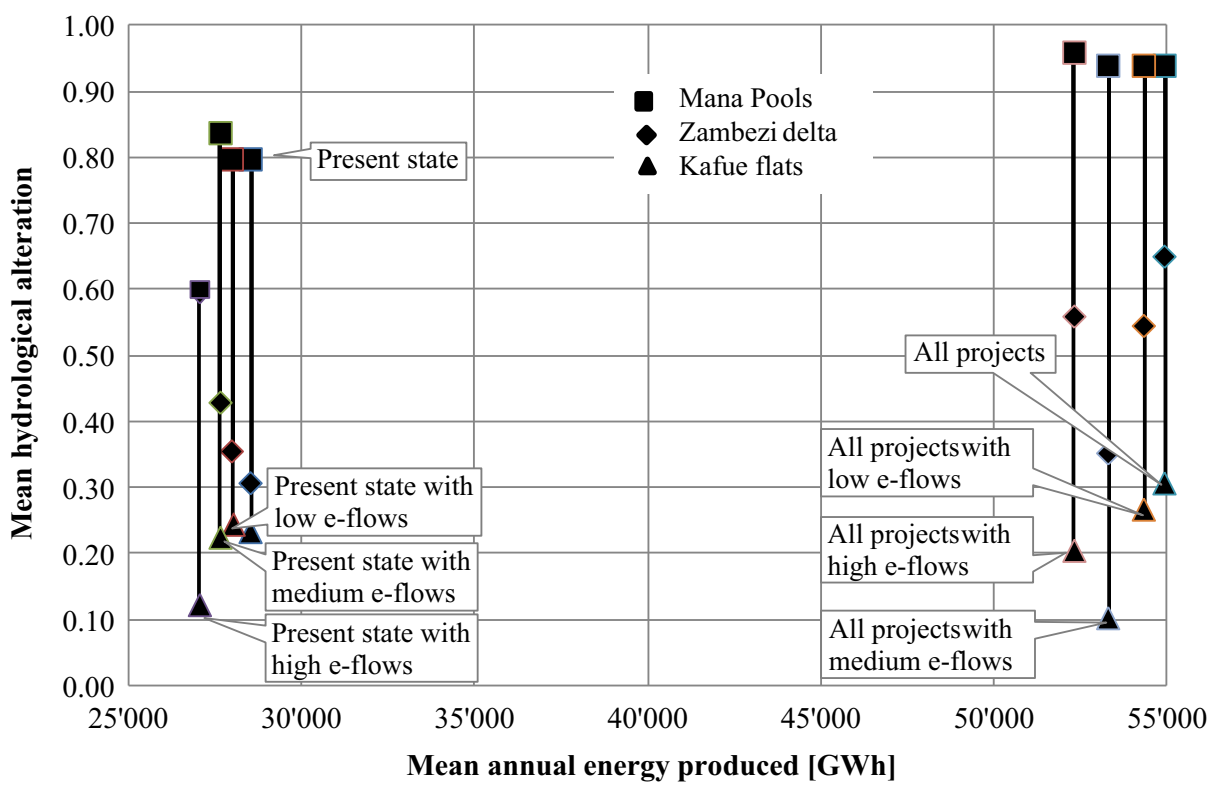

Fig. 4 Total mean annual energy produced versus mean hydrological alteration at Kafue flats, Mana Pools and Zambezi delta for the present state and the future state scenarios with low, medium and high e-flows

The impacts can be mitigated by the implementation of medium e-flow release, particularly targeting the Kafue flats and the Mana Pools, with an estimated loss of only $3 \%$ in energy production. The reason is that for high e-flows, the Itezhi-Tezhi reservoir is emptied and therefore cannot release e-flows over a few years. Similarly, at the Mana Pools, the situation is also not improved by high e-flows because under such a scenario the Kariba reservoir is maintained at a low level as a consequence of the increase of turbine capacity and cannot release the e-flows over large periods. In the Zambezi delta, the effect of e-flows release is also better for the medium e-flows. It may be concluded that a medium e-flow constraint would be sufficient to improve the hydrological conditions in the Kafue flats and the Zambezi delta. This corresponds to an ecologically sustainable development.

\section{Conclusions}

Scenarios combining different levels of environmental requirements as well as multiple hydropower development schemes were simulated at a daily time step by a hydraulichydrologic model in the Zambezi River Basin.

The simulation points toward an actual mean annual energy production of about $30,000 \mathrm{GWh}$ and a firm power level of about 3,000 MW. The impact of the dams on the flow regime is characterized as low on the Kafue flats, high on the Mana Pools and low on the Zambezi delta. Restoring floods by e-flow release reduces the impact of the dams to a lower level on the Kafue flats and a medium level on the Mana Pools. The global loss of the mean annual energy production is below $4 \%$ for the low and medium e-flows and reaches $5 \%$ for high e-flows.

The new planned run-of-river hydropower schemes (Batoka, Kafue Lower, Mphanda Nkuwa and Kholombidzo) allow the mean energy produced to be increased by more than 
$90 \%$ and the firm power by about $40 \%$. Releasing medium e-flows keeps the impact on the Kafue flats to a low level and reduces the impact on the Zambezi delta to a medium level, resulting in a loss of less than $10 \%$ in terms of mean annual energy and about $15 \%$ in terms of firm power. In general, the release of e-flows along with the hydropower development of the basin could keep the impact on the flow regime at the same level as in the actual state, while substantially increasing the energy production. The analysis shows that it is possible to reach a compromise between energy production and environmental sustainability.

Some remarks should be useful for further studies. (1) It is assumed that the turbines on average work at $70 \%$ of their maximum capacity. However, the full capacity could be exploited especially during the period of e-flow release, which would reduce the losses in energy production. (2) Since the inter-annual variability of flow is very high, the idea of defining the e-flow each year depending on the rainy season prevision should be examined.

\section{References}

Arnold JG, Srinivasan R, Muttiah RS, Williams JR (1998) Large area hydrologic modeling and assessment part I: model development. J Am Water Resour Assoc 34(1):73-89

Arthington AH, Bunn SE, Poff NL, Naiman RJ (2006) The challenge of providing environmental flow rules to sustain river ecosystems. Ecol Appl 16(4):1311-1318

Beilfuss R (2010) Modelling trade-offs between hydropower generation and environmental flow scenarios: a case study of the Lower Zambezi River Basin, Mozambique. Int J River Basin Manag 8(3-4):331-347

Beilfuss R (2012) A risky climate for Southern African hydro - assessing hydrological risks and consequences for Zambezi River Basin damsRep., Berkeley, USA

Beilfuss R, Brown C (2010) Assessing environmental flow requirements and trade-offs for the Lower Zambezi River and Delta, Mozambique. Int J River Basin Manage 8(2):127-138

Beilfuss R, Dos Santos D (2001) Patterns of hydrological change in the Zambezi Delta, Mozambique. In Working paper 2, Program for the sustainable management of Cahora Bassa Dam and the lower Zambezi Valley, edited, International Crane Foundation

Cohen Liechti T, Matos JP, Boillat JL, Schleiss AJ (2012) Comparison and evaluation of satellite derived precipitation products for hydrological modeling of the Zambezi River Basin. Hydrol Earth Syst Sci 16(2): 489-500

Cohen Liechti T, Matos JP, Ferràs Segura D, Boillat J-L, and Schleiss AJ (2014) Hydrological modeling of the Zambezi River Basin taking into account floodplain behavior by a modified reservoir approach. Int J River Basin Manage

Cohen Liechti T, Matos JP, Boillat JL, Portela MM, and Schleiss AJ (2014) Hydraulic-hydrologic model for water resources management ofthe Zambezi basin. J Appl Water Eng Res 1-13. doi:10.1080/23249676. 2014.958581

Comair GF, McKinney DC, Maidment DR, Espinoza G, Sangiredy H, Fayad A, Salas FR (2014) Hydrology of the Jordan River Basin: a GIS-based system to better guide water resources management and decision making. Water Resour Manag 28(4):933-946

Dessu SB, Melesse AM (2012) Modelling the rainfall-runoff process of the Mara River basin using the soil and water assessment tool. Hydrol Process 26(26):4038-4049

FAO (1995), Digital soil map of the world and derived soil properties version 3.5 [CD-ROM], In: Land and water digital media series, edited, Rome, Italy

Fekete, BM, Vörösmarty CJ and Grabs W (1999), Global, composite runoff fields based on observed river discharge and simulated water balancesRep., Koblenz, Germany

Gandolfi C, Guariso G, Togni D (1997) Optimal flow allocation in the Zambezi River system. Water Resour Manag 11(5):377-393

Hargreaves GH, Samani ZA (1985) Reference crop evapotranspiration from temperature. Appl Eng Agric 1(2):96-99

Harrison GP, Whittington HW (2002) Susceptibility of the Batoka Gorge hydroelectric scheme to climate change. J Hydrol 264(1-4):230-241

Harrison D, Opperman J, Richter B (2007) Can hydropower be sustainable? Int Water Power Dam Constr 59(10):22-25

International Commission On Large Dams (2007), Dams and the world's waterRep., Paris, France

International Commission On Large Dams (2012), World declaration. Water storage for sustainable development, edited 
Kanamitsu M, Ebisuzaki W, Woollen J, Yang S-K, Hnilo JJ, Fiorino M, Potter GL (2002) NCEP-DOE AMIP-II Reanalysis (R-2). Bull Am Meteorol Soc 83(11):1631-1643

Mango LM, Melesse AM, McClain ME, Gann D, Setegn SG (2011) Land use and climate change impacts on the hydrology of the upper Mara River Basin, Kenya: results of a modeling study to support better resource management. Hydrol Earth Syst Sci 15(7):2245-2258

Matos JP, Cohen T, Boillat JL, Schleiss AJ, and Portela MM (2010), Analysis of flow regime changes due to operation of large reservoirs on the Zambezi River, paper presented at 6th International Symposium on Environmental Hydraulics, Taylor and Francis Group, London, Athens, Greece, 23-25 June 2010

Meile T, Boillat JL, Schleiss AJ (2011) Hydropeaking indicators for characterization of the Upper-Rhone River in Switzerland. Aquat Sci 73(1):171-182

Moore AE, Cotterill FPD, Main MPL, and Williams HB (2007), The Zambezi River. Large Rivers, 311-332

Neitsch SL, Arnold JG, Kiniry JR and Williams JR (2009), Soil and water assessment tool theoretical documentation (Version 2009), edited, Temple, Texas

Ostadrahimi L, Mariño MA, Afshar A (2012) Multi-reservoir operation rules: multi-swarm PSO-based optimization approach. Water Resour Manag 26(2):407-427

Richter BD and Thomas GA (2007), Restoring environmental flows by modifying dam operations. Ecol Soc 12(1), art. no. 12

Richter BD, Baumgartner JV, Wigington R, Braun DP (1997) How much water does a river need? Freshw Biol 37(1):231-249

Richter BD, Baumgartner JV, Braun DP, Powell J (1998) A spatial assessment of hydrologic alteration within a river network. River Res Appl 14(4):329-340

Schuol J, Abbaspour KC, Yang H, Srinivasan R and Zehnder AJB (2008), Modeling blue and green water availability in Africa. Water Resour Res 44(7), art. no. W07406

The World Bank (2010) The Zambezi River Basin A Multi-Sector Investment Opportunities Analysis. The World Bank, Washington

Tilmant A, Beevers L, and Muyunda B (2010), Restoring a flow regime through the coordinated operation of a multireservoir system: the case of the Zambezi River basin. Water Resour Res 46(7), art. no. W07533

Tilmant A, Kinzelbach W, Juizo D, Beevers L, Senn DB, Casarotto C (2012) Economic valuation of benefits and costs associated with the coordinated development and management of the Zambezi river basin. Water Policy 14(3):490-508

United Nations Development Programme (2006) Human development report, beyond scarcity: power, poverty and the global water crisisRep. UNDP, New York

USDA Soil Conservation Service (1972) SCS National engineering handbook section 4: hydrology. Washington DC, USA

Vörösmarty CJ, Moore B III (1991) Modeling basin-scale hydrology in support of physical climate and global biogeochemical studies: An example using the Zambezi River. Surv Geophys 12(1-3):271-311

Vrugt JA, Robinson BA (2007) Improved evolutionary optimization from genetically adaptive multimethod search. Proc Natl Acad Sci U S A 104(3):708-711

Vrugt JA, Robinson BA, Hyman JM (2009) Self-adaptive multimethod search for global optimization in realparameter spaces. IEEE Trans Evol Comput 13(2):243-259

Yin XA, Yang ZF and Petts GE (2011) Reservoir operating rules to sustain environmental flows in regulated rivers. Water Resour Res 47(8), art. no. 7206

Yin XA, Yang ZF, Petts GE (2012) Optimizing environmental flows below dams. River Res Appl 28(6):703-716

Zhang XM, Wang LP, Li JW, Zhang YK (2013) Self-optimization simulation model of short-term cascaded hydroelectric system dispatching based on the daily load curve. Water Resour Manag 27(15):5045-5067 